\title{
The Relevance of K-12 Engineering Curricula to NGSS: An Analysis of TeachEngineering NGSS Alignments (RTP Strand 1)
}

\section{Carleigh Samson, University of Colorado Boulder and TeachEngineering}

Carleigh Samson is a research associate and Ph.D. student at the University of Colorado Boulder. As a former secondary mathematics teacher and three-year K-12 engineering teaching fellow holding graduate degrees in both Civil Engineering from the University of Colorado Boulder and Secondary Education from The Johns Hopkins University, Carleigh has broad K-12 classroom teaching experience as well as deep conceptual and pedagogical knowledge in engineering and education. Carleigh works extensively on K-12 engineering curriculum development with the TeachEngineering digital library and has led the initiative to align the collection's 1325+ lessons and hands-on activities with the Next Generation Science Standards.

\section{Jacquelyn Sullivan PhD, TeachEngineering Project Leader, University of Colorado Boulder}

Sullivan is project leader for the multi-institution TeachEngineering digital library, comprised of over 1325 classroom-tested engineering lessons and hands-on activities for use in K-12 classrooms. She is also founding Co-director of the CU Teach Engineering program, a unique pathway to secondary science and math teacher licensure through a design-focused General Engineering degree. The CU Teach Engineering program relies heavily on the TeachEngineering digital library to provide K-12 engineering curricular content.

\section{Rene F. Reitsma , PhD, Oregon State University, College of Business}

René F. Reitsma studied Human Geography and Policy Sciences at the University of Nijmegen, The Netherlands. He is a Professor of Business Information Systems at Oregon State University. While at the University of Colorado at Boulder, Reitsma worked on the development and research of information systems for reservoir and river management in various river basins in the western US. More recent work concentrates on the development and research of real-time engineering information systems and digital libraries for undergraduate and K-12 learning. Reitsma's research concentrates on how people apply information systems to solve problems with emphasis digital library navigation.

\section{Michael Soltys PhD, University of Colorado, Boulder}

General Engineering Plus Program, University of Colorado Boulder 


\section{The Relevance of K-12 Engineering Curricula to NGSS: An Analysis of TeachEngineering-NGSS Alignments (RTP Strand 1)}

\section{Introduction}

The 2013 publication of the Next Generation Science Standards (NGSS) provided the first widely adopted set of science standards to include engineering design throughout all K-12 grades. In doing so, NGSS raised the relevance of the K-12 engineering education sector on a national scale. The TeachEngineering digital library (https://www.teachengineering.org/), representative of the K-12 engineering education sector through its collaboration of 36, mostly NSF-funded, K-12 engineering education programs across the US, recently aligned its 1,300+ K12 engineering lessons and hands-on activities to the NGSS. This paper provides analysis of both the alignment process and its results. As such, we offer insight into the correspondence between the NGSS and a broad, collection of K-12 engineering learning objects and hence, into the mutual relevance of K-12 engineering curriculum and the NGSS. We also provide some recommendations for future K-12 engineering curriculum development.

\section{Background: TeachEngineering and NGSS}

The TeachEngineering digital library is a collaborative project engaging university faculty, graduate engineering students and K-12 teachers in long-term curriculum development and dissemination focused on K-12 engineering education. Originally started with five university partners who designed and created curricular content through NSF GK-12 engineering grants, the TeachEngineering digital library now comprises more than 1,300 lessons and hands-on activities contributed by 36 US institutions, including 30 NSF-funded GK-12 and RET engineering education grants, each engaged in practice with local school districts. Providing free access, the TeachEngineering digital library was accessed by more than $2 \mathrm{M}$ unique users in the last year, with its usage growing at approximately 50\% over that same time period.

TeachEngineering is a standards-aligned curricular resource aimed at engaging students in exploring real-world engineering and engineering design principles. All lessons and hands-on activities are aligned to state, national and international education standards. Since curricula are submitted for publication from dozens of contributors, each lesson and activity is aligned to state science, mathematics, and in some cases, engineering and/or technology education standards from the author's home state as well as to the Standards for Technological Literacy (STL) developed by the International Technology and Engineering Educators Association (ITEEA, 2007).

The TeachEngineering team viewed the NGSS release as an unprecedented opportunity to deliver meaningful K-12 engineering curriculum to educators nationwide. In addition to the recently released Common Core Math Standards (CCMS), the NGSS challenges K-12 educators to redesign their teaching methods to promote active student involvement in the learning process. Its Performance Expectations include higher-level learning accomplishments ${ }^{1}$, such as plan and conduct, show, analyze, develop and evaluate, to ensure that students are actively engaged in their learning, so as to attain learning levels beyond recollection and understanding. 
The NGSS also challenge K-12 teachers to incorporate engineering design at all grade levels. Project-based learning, in the form of engineering design projects using an analysis-informed design process, have been shown to increase student achievement in math and science subject areas in studies in which teachers are trained or already familiar with the relevant pedagogical studies. ${ }^{2,3}$ Hirsch et al. ${ }^{4}$ found in their Pre-Engineering Instructional and Outreach Program that many teachers possessed limited knowledge of engineering careers and had low self-efficacy in terms of preparing students for engineering careers before participating in the program's workshop. Hence, the Hirsch et al. study foreshadowed that with the implementation of the NGSS, many teachers would find themselves responsible for their students meeting engineering design learning objectives, yet feel personally unprepared to teach engineering.

The new challenges facing teachers in providing meaningful hands-on engineering activities and in teaching potentially unfamiliar content such as engineering design motivated the TeachEngineering digital library to embark on aligning its entire collection to both the NGSS and the CCMS.

\section{NGSS Alignment Project}

We focused the NGSS alignment effort on the Performance Expectations, a subset of 208 NGSS standards that integrate the three NGSS dimensions: Science and Engineering Practices, Disciplinary Core Ideas and Crosscutting Concepts. The performance expectations are arranged in 12 topics (see Table 1).

Initial attempts to align a small subset of TeachEngineering curricula yielded several difficulties. Since each NGSS performance expectation was written to incorporate science and engineering practices, disciplinary core ideas and crosscutting concepts ${ }^{5}$, the NGSS standards have a complexity that is frequently not met in its entirety by a given TeachEngineering lesson or activity. As a consequence, a number of items were cataloged as only "partially aligned." Such partial alignment took several forms. In most cases, the TeachEngineering curriculum addressed some, but not all of the aspects expressed in a performance expectation standard. In some cases the items matched the general NGSS performance expectation, but did not teach to the specific idea or use the vocabulary highlighted in the standard. The following examples illustrate the partial alignment challenge:

Example 1: Performance expectation HS-PS3-5 states: Develop and use a model of two objects interacting through electric or magnetic fields to illustrate the forces between objects and the changes in energy of the objects due to the interaction. During the initial step of the alignment project, one aligner identified an activity in which students use a magnet and iron filings to visualize magnetic field lines and assigned it a partial alignment to this standard because, even though the activity involves students using a model of two objects interacting through a magnetic field (which illustrates the force between objects), the aligner identified that students did not discuss or identify the changes in energy of the objects.

Example 2: An activity based on graphing the spread of disease was identified as partial alignment to the performance expectation HS-ETS1-4: Use a computer simulation to model the impact of proposed solutions to a complex real-world problem with numerous criteria and constraints on interactions within and between systems relevant to the problem. In the 
TeachEngineering activity, students use a computer simulation to model a complex realworld problem, but do not model the impact of proposed solutions.

This "partial alignment" difficulty is in line with the observations offered by Reitsma and Diekema $^{6}$ and Marshall and Reitsma ${ }^{7}$ in the context of automated standards alignment. These authors observe that whereas automated alignment techniques perform relatively well on the empirical or "domain" aspects of standards, the techniques have far greater difficulty correctly aligning the methodological content of standards. Modern standards sets that tend to integrate domain and method aspects into single standards present challenges for aligning curricula. Note that whereas the first example represents a mix of both domain (magnetism, iron, electric/magnetic fields) and method aspects (model building), the second standard is essentially all method.

Our next challenge was lack of inter-rater reliability, i.e., inconsistent alignments between catalogers. Inter-rater reliability problems are common in K-12 standards alignment exercises, as previously observed by, for instance, Devaul et al. ${ }^{8}$, Reitsma et al. ${ }^{9}$, and Reitsma and Diekema ${ }^{6}$.

Finally, some TeachEngineering engineering activities and lessons did not align to any NGSS standards, which, after all, are explicitly science standards.

To address these challenges, the TeachEngineering team designed a three-step alignment process:

1. Two engineering students independently aligned each TeachEngineering curricular item to the NGSS performance expectations. Each cataloger read the item and reviewed the standards corresponding with the item's grade band (plus and minus one grade level) prior to making an alignment decision. Items were classified as having no alignment, partial alignment or full alignment. For full alignments, catalogers could select one or more performance expectations. In the case of partial alignments, the cataloger selected the performance expectation that represented the closest fit.

2. Graduate K-12 engineering Fellows with experience teaching engineering in K-12 classrooms, modified the partially aligned curricular items to meet full alignment. First they confirmed that the suggested performance expectation was the closest fit, or identified a more appropriate one. Next, they modified the lesson or activity to fully align to the performance expectation. Their curricular modifications were subsequently reviewed and edited by TeachEngineering editors and the lesson or activity was published online in a (now) full alignment status. If the Fellow ascertained that no reasonable curricular modifications could be made to achieve full alignment, the item's status was designated as no alignment.

3. A concordance analysis represented the third stage of the alignment process. In this phase, a TeachEngineering editor - a former secondary STEM teacher holding both graduate education and engineering degrees - compared the two independent alignment recommendations made for each item. In cases of dual full alignment, the performance expectation alignment was indicated for the curricular item. If differing full alignments were identified, the editor made the final decision on which was appropriate. In cases of 
inconsistent alignments concerning full $v s$. partial alignment, a K-12 Fellow determined whether the lesson or activity needed curricular augmentation to meet full alignment.

To ensure that new additions to the TeachEngineering collection are also aligned, new authors are now asked to align their curricular submissions to NGSS, as well as CCMS.

Peer Review. Every item submitted to the TeachEngineering digital library is peer-reviewed by an unaffiliated engineer and an unaffiliated K-12 educator for accuracy of engineering, science and mathematical content, pedagogy, grade-level appropriateness and accessibility to teachers. The K-12 educator also reviews the author-provided standards alignments. More specifically, teacher reviewers assess whether 1) the educational standards are at the appropriate comprehension or knowledge level for the targeted grade range, 2) student actions are clear and likely to yield the standard's objective, and 3) the provided assessment tools serve to adequately assess the standard(s). If accepted-for-publication lessons and activities are found lacking in NGSS and/or CCMS alignments, a TeachEngineering editor makes appropriate alignments before publication.

After examining all lessons and activities, approximately $80 \%$ of the TeachEngineering collection has alignments to NGSS performance expectations, with 1,598 alignments distributed over 1,026 lessons and activities (for an average of 1.5 standards per aligned document). Approximately $20 \%$ of the items required curricular augmentation in order to attain full NGSS performance expectation alignment.

\section{Analysis of TeachEngineering --NGSS Coverage}

Alignment of the NGSS standards with the TeachEngineering collection concentrated on the 208 Performance Expectations, 135 ( 65\%) of which have at least one alignment in the collection's lessons or activities. The distribution of these alignments to the performance expectation standards follows an exponential pattern (Figure 1). Notably, 75\% of the NGSS standards each have alignments to fewer than 15 TeachEngineering lessons and activities, while three standards each have alignments to more than 100 TeachEngineering lessons and activities.

The three NGSS performance expectation standards each aligned to more than 100 lessons and activities are all within the Engineering Design topic. The standard with the highest number of alignments to TeachEngineering curricula (119 lessons and activities) is an Engineering Design standard for grades 3-5 in which students define a simple design problem. The standard with the second highest number of TeachEngineering alignments (115 lessons and activities) is based on middle school students defining the criteria and constraints of a problem. Three additional NGSS performance expectations are aligned to more than 60 lessons and activities - all within the Engineering Design topic at grades 3-5 and 6-8.

It is evident that the lessons and hands-on activities in the TeachEngineering collection, expressly created to teach engineering concepts, provide a wealth of curricular resources to enable students to meet the Engineering Design performance expectations, especially for grades 3-8. On the other hand, the collection provides only a handful, on average, of lessons and activities that align to the remaining NGSS performance expectations. Reflecting back that the collection's contents were created by more than 35 engineering colleges - most by NSF 
grantees - one can reasonably conclude that these findings (and opportunities for future work) are broadly representative of K-12 engineering curriculum created by engineering educators and their partner teachers.

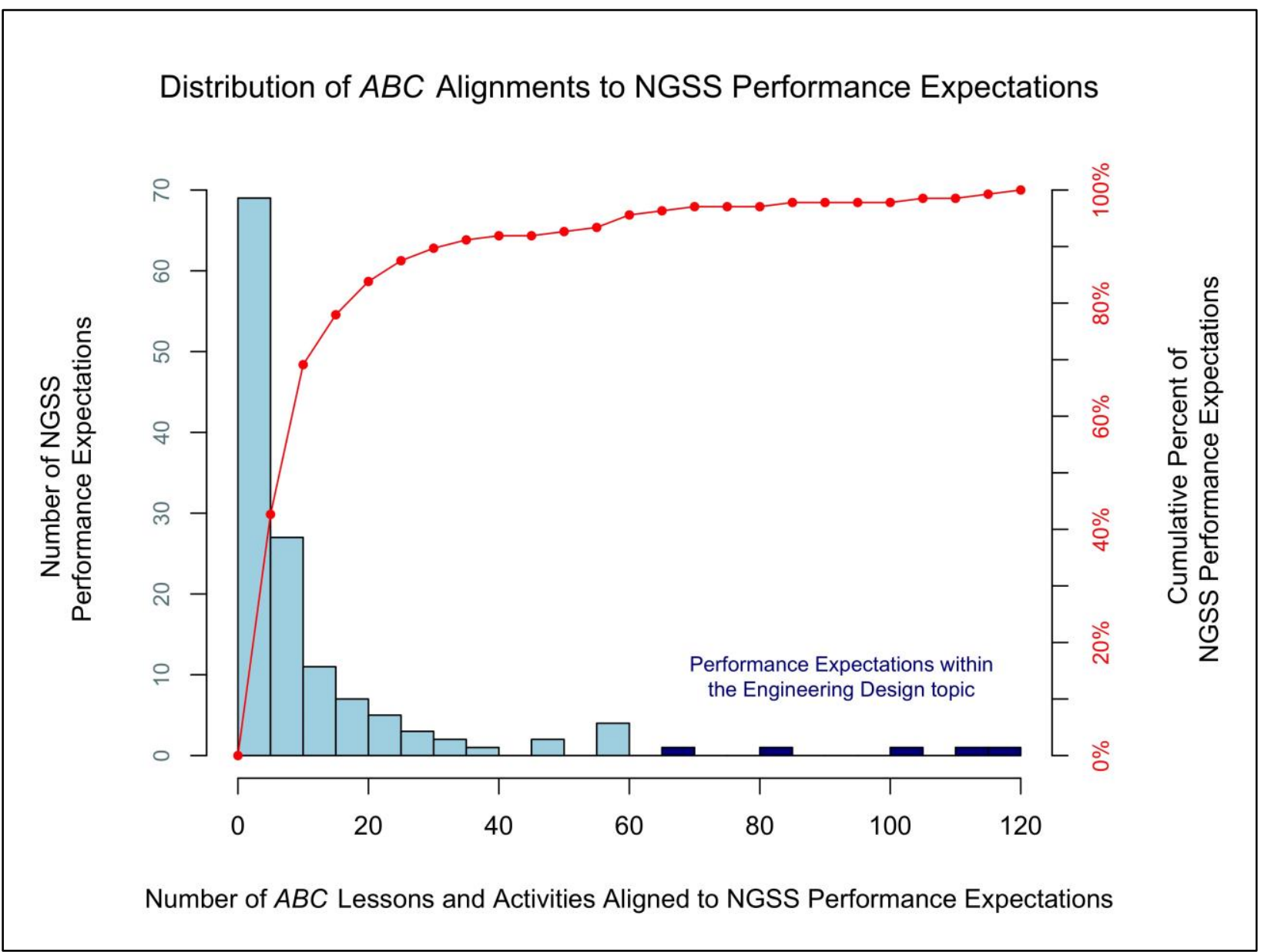

Figure 1. Number of NGSS Performance Expectation standards differentiated by frequency of alignment to TeachEngineering lessons and activities.

Table 1 displays the alignment counts for the Performance Expectations arranged by their 12 topical areas and summed over the traditional K-12 grade-level bands of elementary, middle and high school. We observe the following:

- On average, each of the 208 NGSS performance expectations is aligned with about six lessons and activities $(1,332 / 208)$ in the TeachEngineering collection (also see Figure 1).

- The distribution of alignments by grade band across all standards is $\sim 35 \%$ elementary, $45 \%$ middle school and $20 \%$ high school (see Table 1 bottom row), closely matching the grade level distribution of all lessons and activities in the TeachEngineering collection (33\% elementary, $42 \%$ middle school and 24\% high school; see Figure 2). Despite generally matching, we observe a slight underrepresentation of NGSS standards alignment within our high-school curricula ( $20 \%$ vs. 24\%), indicating that the high school-level lessons and activities within the TeachEngineering collection tend to have relatively fewer alignments to 
the NGSS performance expectations compared with the middle- and elementary school-level curricula.

Table 1. NGSS Performance Expectations by topic and their alignments to TeachEngineering lessons and activities.

\begin{tabular}{|c|c|c|c|c|c|c|}
\hline \multirow[t]{2}{*}{$\begin{array}{l}\text { NGSS } \\
\text { Topic }\end{array}$} & \multirow{2}{*}{$\begin{array}{l}\text { Total Number } \\
\text { of } \\
\text { Performance } \\
\text { Expectations }\end{array}$} & \multirow{2}{*}{$\begin{array}{l}\text { Performance } \\
\text { Expectations } \\
\text { with Teach- } \\
\text { Engineering } \\
\text { Alignments }\end{array}$} & \multirow{2}{*}{$\begin{array}{l}\text { Total \# of Teach- } \\
\text { Engineering } \\
\text { Lessons and } \\
\text { Activities } \\
\text { Aligned }\end{array}$} & \multicolumn{3}{|c|}{$\begin{array}{c}\text { Number of } \\
\text { TeachEngineering Lessons } \\
\text { and Activities Aligned } \\
\text { by Grade Level }\end{array}$} \\
\hline & & & & $\begin{array}{l}\text { Elem. } \\
(\text { K-5) }\end{array}$ & $\begin{array}{c}\text { Middle } \\
(6-8)\end{array}$ & $\begin{array}{c}\text { High } \\
(9-12)\end{array}$ \\
\hline $\begin{array}{l}\text { Biological Evolution: } \\
\text { Unity and Diversity }\end{array}$ & 17 & $5(29 \%)$ & 12 & 10 & 2 & $\mathbf{0}$ \\
\hline $\begin{array}{l}\text { Earth and Human } \\
\text { Activity }\end{array}$ & 18 & $11(61 \%)$ & 198 & 88 & 92 & 18 \\
\hline $\begin{array}{l}\text { Earth's Place in the } \\
\text { Universe }\end{array}$ & 16 & $7 \quad(44 \%)$ & 20 & 5 & 14 & 1 \\
\hline Earth's Systems & 24 & $15(63 \%)$ & 78 & 28 & 45 & 5 \\
\hline $\begin{array}{l}\text { Ecosystems: } \\
\text { Interactions, Energy } \\
\text { and Dynamics }\end{array}$ & 17 & $10(59 \%)$ & 37 & 11 & 19 & 7 \\
\hline Energy & 17 & $15(88 \%)$ & 148 & 51 & 40 & 57 \\
\hline Engineering Design & 14 & $14(100 \%)$ & 479 & 170 & 215 & 94 \\
\hline $\begin{array}{l}\text { From Molecules to } \\
\text { Organisms: } \\
\text { Structures and } \\
\text { Processes }\end{array}$ & 22 & $14(64 \%)$ & 85 & 19 & 56 & 10 \\
\hline $\begin{array}{l}\text { Heredity: Inheritance } \\
\text { and Variation of } \\
\text { Traits }\end{array}$ & 8 & $4 \quad(50 \%)$ & 11 & 1 & 3 & 7 \\
\hline $\begin{array}{l}\text { Matter and Its } \\
\text { Interactions }\end{array}$ & 22 & $14(64 \%)$ & 66 & 32 & 18 & 16 \\
\hline $\begin{array}{l}\text { Motion and Stability: } \\
\text { Forces and } \\
\text { Interactions }\end{array}$ & 18 & $16(89 \%)$ & 145 & 41 & 67 & 37 \\
\hline $\begin{array}{l}\text { Waves and their } \\
\text { Applications in } \\
\text { Technologies for } \\
\text { Information Transfer }\end{array}$ & 15 & $10(67 \%)$ & 53 & 17 & 23 & 13 \\
\hline $\begin{array}{l}\text { Grand Total Count } \\
\text { Aligned Documents } \\
\text { and Alignments }\end{array}$ & 208 & 135 & 1,332 & 473 & 594 & 265 \\
\hline $\begin{array}{l}\text { Grand Total \% } \\
\text { Aligned Documents } \\
\text { and Alignments }\end{array}$ & & $65 \%$ & & $35 \%$ & $45 \%$ & $20 \%$ \\
\hline
\end{tabular}




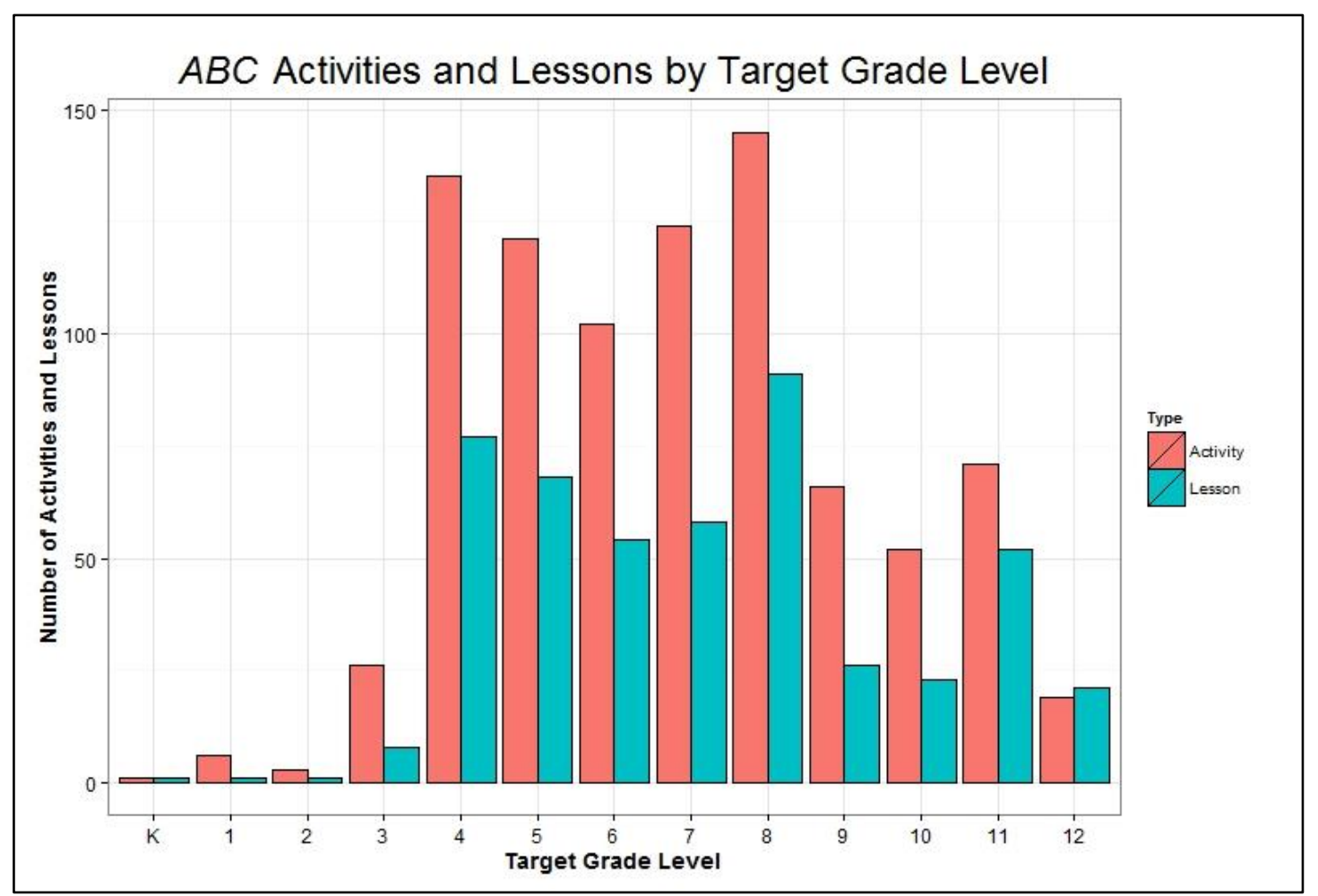

Figure 2. Distribution of the TeachEngineering collection documents by target grade level.

- Comparatively little coverage exists of primarily "science-oriented" topics such as Heredity, Biological Evolution or Earth's Place in the Universe. At the high school level, proportionally even less alignment exists to standards within these topics. Although these topics clearly have engineering aspects and connections, their more pure science nature makes them harder to fit with engineering than their more "applied" siblings.

\section{TeachEngineering Usage Analysis}

The opportunity presented by the NGSS to the K-12 engineering education sector is evidenced by the increased demand by TeachEngineering users for TeachEngineering curricular resources aligned to NGSS. Between 2013 and 2014, the number of users arriving at the TeachEngineering collection from an Internet search including the keyword NGSS more than quadrupled. To investigate changes in demand, user sessions were tracked using Google Analytics during the entire NGSS alignment process. For the purposes of this paper, we compared session data from the July 1 - December 31,2013, time frame; i.e., during the start of the NGSS alignment process, with the same time period in 2014 after most of the TeachEngineering curriculum was aligned. The total number of sessions originating from the U.S. increased $76 \%$ over this time period, and much of this usage growth is attributable to factors other than NGSS alignment. Thus, perhaps a better, although not perfect, assessment of NGSS alignment influence on TeachEngineering usage is a comparison of usage from states that have adopted NGSS to those that have not. We found that whereas viewership from "NGSS states" increased $85 \%$ during the time period, viewership growth in "non-NGSS states" increased 73\%, indicating a strong, statistically significant relationship between NGSS adoption and demand for engineering-related curriculum $\left(\chi^{2}=160, \mathrm{df}=1, \mathrm{p}<.001\right)$. 


\section{Common Core Math Alignment}

During the last four years, the nation has also seen widespread (and increasingly contentious) implementation of the Common Core State Standards. This set of English and mathematics standards is designed to provide a clear and consistent framework for educators while readying students for college and careers. The math portion of the Common Core consists of 455 unique standards divided among 16 domains.

The TeachEngineering digital library also viewed the implementation of the Common Core as an opportunity to emphasize the connection between mathematics and engineering analysis, and put engineering-related curricula into the hands of K-12 math educators. Applying the multi-step alignment processed developed for the NGSS, TeachEngineering manually aligned TeachEngineering's engineering lessons and hands-on activities to the Common Core Math Standards (CCMS). The collection now has 205 CCMS alignments, distributed over 655 activities and lessons, for an average of three documents per aligned standard.

\section{Observations and Recommendations}

Reflecting on the results of the analysis of the NGSS alignment process and the resulting NGSS and CCMS alignment coverage by TeachEngineering, we offer some observations and recommendations for future K-12 engineering curriculum design.

1. Aligning existing curriculum to the NGSS can be challenging and labor intensive. As illustrated by the multi-step process presented above, a meticulous review by several dedicated people was required - a minimum of three people played an active role in the alignment of any given lesson or activity. The necessity of this multi-step process was driven by low inter-rater reliability and high likelihood of partial alignment.

2. The identification of partial alignments highlighted the complexity and specificity of the NGSS performance expectations, which proved to be a major factor in the alignment and inter-rater reliability challenges. The level of specificity increases in the high school level NGSS performance expectations, resulting in proportionally fewer NGSS standards matches achieved at the high school level.

3. TeachEngineering provides curricular resources to meet approximately $65 \%$ of the NGSS performance expectations, leaving 73 performance expectations without alignments. As identified in the NGSS Coverage section above, TeachEngineering had the fewest alignments to the Heredity, Biological Evolution, and Earth's Place in the Universe topics. Put differently, TeachEngineering aligns to only $29 \%$ of the Biological Evolution standards, $44 \%$ of the Earth's Place in the Universe standards, and 50\% of the Heredity standards. As written, these standards cover more pure science topics without broad engineering applications. Hence, the dozens of TeachEngineering K-12 engineering curriculum developers have unwittingly addressed these topics far less often than more applied engineering science topics, as evidenced by the curricular content of the TeachEngineering digital library. 
4. TeachEngineering lessons and activities provide "engineering science" content that is either not included at all in the NGSS performance expectations or not included in the NGSS performance expectations for the grade level that the curricula address.

Example 1: While the TeachEngineering digital library has a number of lessons and activities addressing surface tension, no NGSS performance expectations specifically mention surface tension. The performance expectation HS-ESS2-5, Plan and conduct an investigation of the properties of water and its effects on Earth materials and surface processes, could be interpreted to include surface tension, although the clarification statement provided by NGSS for this performance expectation and the corresponding disciplinary core ideas do not touch upon surface tension. This high school-level standard is the closest standard for addressing surface tension; no middle school-level performance expectations exist for teaching students about this concept.

Example 2: Similarly, TeachEngineering provides many resources for teaching students about acid and base chemistry, but NGSS performance expectations are absent on this topic.

These two example topics, as well as many other "engineering science" topics, are essential and pervasive in certain engineering realms, and help to illustrate why K-12 engineering curriculum development should not be solely based on the NGSS topical areas.

5. Although the NGSS and CCMS standards sets are similar in size, only about $50 \%$ of the TeachEngineering collection aligned to the CCMS. Seemingly, the crossover between science and engineering appears more obvious to K-12 engineering curriculum developers than the integration of math; thus, more lessons and activities are developed focusing on engineering science. In doing so, curriculum developers "slight" the analysis aspect of the engineering design process in which mathematical calculations are indispensable for making predictions and informing design evolution.

Recommendations for Future K-12 Engineering Curriculum Design

1. Purposefully designing engaging hands-on engineering curriculum to meet specific NGSS performance expectations provides the potential for high impact. This study brings to light the challenge that TeachEngineering faced in aligning pre-existing curriculum, necessitating extensive curricular modification in order to ensure that all aspects of the NGSS performance expectations were met. In lessons in particular, augmentations focused on ensuring that students have active roles in the learning process - a fundamental NGSS concept. The most effective approach to provide rich K-12 engineering resources for K-12 teachers addressing NGSS expectations is to start with the NGSS performance expectations as a guide for curriculum development.

2. If we consider TeachEngineering as a representation of the $\mathrm{K}-12$ engineering education sector, this study revealed that the gaps in alignment- the NGSS performance expectations that were not aligned to any TeachEngineering curriculum - may represent gaps in engineering science topics within K-12 engineering curriculum. While classical physics topics such as energy and forces have obvious connections to engineering, the more "pure" 
science topics included in the NGSS (such as Heredity, Biological Evolution, or Earth's Place in the Universe) that saw the fewest alignments exist ubiquitously as fundamental topics for many engineering fields such as environmental engineering, aerospace engineering, genetic engineering, and biomedical engineering, among others. A great opportunity exists for K-12 engineering curriculum developers to focus on these overlooked science topics to creatively teach the concepts in the context of their real-world engineering connections.

3. In order to differentiate the true engineering design process from trial and error design, K-12 engineering curriculum must incorporate both mathematics and science into engineering analysis. While this study shows that existing K-12 engineering curricula pair strongly with the NGSS, the number of lessons and activities in the TeachEngineering collection that align to CCMS is much lower. It is recommended that K-12 engineering curriculum developers strive to incorporate more mathematics in engineering design curriculum, showcasing its vital role in informing the design process, and more fully preparing students for college-level and beyond engineering.

\section{Acknowledgments}

This material is based upon work supported by the National Science Foundation under grant numbers DUE 0226322 and DUE 0532709. The authors express their sincere appreciation for additional funding from the Gates Frontiers Fund to support the 18-month NGSS and CCMS alignment project.

\section{References}

1. Bloom, B. S., Engelhart, M. D., Furst, E. J., Hill, W. H., \& Krathwohl, D. R (1956). Taxonomy of Educational Objectives: The Classification of Educational Goals. Handbook I: Cognitive Domain. New York, NY: David McKay Company.

2. Akins, L. \& Burghardt, D. (2006) Work in Progress: Improving K-12 Mathematics Understanding with Engineering Design Projects. $36^{\text {th }}$ ASEE/IEEE Frontiers in Education Conference, M3C-14, October 28-31, 2006, San Diego, CA. Accessed 1/16/2015. http://ieeexplore.ieee.org/stamp/stamp.jsp?tp=\&arnumber=4116869

3. Bottoms, G. \& Anthony, K. (2005) Project Lead the Way: A Pre-Engineering Curriculum That Works: A New Design for High School Career/Technical Studies. Accessed 1/16/2015. http://publications.sreb.org/2005/05V08_Research_PLTW.pdf

4. Hirsch, L. S., Kimmel, H., Rockland, R., \& Bloom, J. (2005) Implementing Pre-Engineering Curricula in High School Science and Mathematics. $35^{\text {th }}$ ASEE/IEEE Frontiers in Education Conference, S2F-26, Indianapolis, IN, October 19-22, 2005. Accessed 1/16/2015. http://ieeexplore.ieee.org/stamp/stamp.jsp?tp=\&arnumber=1612235

5. Willard, T. (2013) A Look at the Next Generation Science Standards. The Science Teacher, National Science Teachers Association. Accessed 1/13/2015. http://nstahosted.org/pdfs/ngss/InsideTheNGSSBox.pdf

6. Reitsma, R. \& Diekema, A. R. (2011) Comparison of Human and Machine-Based Educational Standard Assignment Networks. International Journal on Digital Libraries, 11, 209-223. 
7. Marshall, B. \& Reitsma, R. (2011) World vs. Method: Educational Standard Formulation Impacts Document Retrieval. Conference Proceedings of the Joint International Conference on Digital Libraries (JCDL 2011), Ottawa, ON, Canada, June 13-17, 2011.

8. Devaul, H., Diekema, A. R., \& Ostwald, J. (2011) Computer-Assisted Assignment of Educational Standards Using Natural Language Processing. Journal of the American Society for Information Science and Technology, 61(12), 395-405.

9. Reitsma, R., Marshall, B., \& Zarske, M. (2010) Aspects of "Relevance" in the Alignment of Curriculum with Educational Standards. Information Processing \& Management, 46(3), 362-37. 